\title{
Pedro de Lorenzo, de director de La Voz de Castilla a proscrito en Burgos
}

\author{
Clara SANZ HERNANDO \\ Universidad de Burgos \\ cshernando@ubu.es
}

Recibido: 25 de abril de 2016

Aceptado: 8 de septiembre de 2016

\begin{abstract}
Resumen
El trabajo saca a la luz los motivos por los que el periodista Pedro de Lorenzo, director del diario del Movimiento en Burgos, La Voz de Castilla, entre noviembre de 1945 y febrero de 1946, fue bruscamente cesado y desterrado de la provincia. El nacimiento del rotativo como una empresa privada que ostentó una doble dirección -la política, a través de la Delegación Nacional de Prensa, y la económica, personalizada en el gobernador civil y jefe provincial del Movimiento, Manuel Yllera-, convirtió a la Redacción en un polvorín donde se dilucidaron las luchas por el control ideológico del periódico.
\end{abstract}

Palabras clave: Pedro de Lorenzo; La Voz de Castilla; prensa; franquismo; Burgos.

\section{Pedro de Lorenzo, from editor of La Voz de Castilla to become an outlaw in Burgos}

\begin{abstract}
The work sheds light on why the journalist Pedro de Lorenzo, editor of the Movement in Burgos, $L a$ Voz de Castilla, between November 1945 and February 1946, was abruptly ceased and banished from the province. The birth of the newspaper as a private company that showed a double direction -politics, through the National Delegation of Press, and economic, custom in civil governor and provincial chief of the Movement, Manuel Yllera-, turned to the editor in a tinderbox where fights were elucidated by the ideological control of the newspaper.
\end{abstract}

Keywords: Pedro de Lorenzo; La Voz de Castilla; press; Franco; Burgos.

\section{Referencia normalizada}

Sanz Hernando, C. (2016). Pedro de Lorenzo, de director de La Voz de Castilla a proscrito en Burgos. Historia y Comunicación Social. Vol 21, número 2, páginas 497-512.

Sumario: 1. Introducción. 2. Estado de la cuestión. 2.1. Un emporio de cabeceras incautadas. 3. Los directores en la prensa franquista. 4. La fundación de $\mathrm{La} \mathrm{Voz} \mathrm{de} \mathrm{Castilla.} \mathrm{5.} \mathrm{La} \mathrm{imposición} \mathrm{de} \mathrm{Pedro} \mathrm{de}$ Lorenzo. 6. El pulso de Yllera. 7. Conclusiones. 8. Referencias bibliográficas. 


\section{Introducción}

El periodista y abogado Pedro de Lorenzo y Morales (1917-1980) fue el segundo director que estuvo al frente de La Voz de Castilla, el periódico de la Prensa del Movimiento en Burgos, último de la cadena en crearse, pues lo hizo el 1 de septiembre de 1945, y uno de los primeros que cerró, el 24 enero de 1976. Su incorporación, para sustituir a Demetrio Ramos, se produjo dos meses después de que la publicación estuviera en la calle.

El paso de Pedro de Lorenzo por el diario burgalés sería breve. En él permaneció de noviembre de 1945 a febrero de 1946. Su traumática salida, junto con la del redactor jefe Eduardo Bort, fue muy sonada en Burgos y constituyó todo un escándalo en aquellos días, pues no solo se les relevó de sus cargos sino que se les conminó a abandonar la provincia. Un destierro en toda regla. El objetivo de este trabajo consiste en profundizar en las causas, circunstancias y consecuencias de un despido del que hasta ahora poco se conocía, más allá de que se produjo por desavenencias con el fundador de $L a V o z$ y a la sazón gobernador civil y jefe provincial del Movimiento, Manuel Yllera. A él no se refiere ni el propio De Lorenzo (1983) en su "Diario de la Mañana", obra en la que repasa su trayectoria profesional, y en la que se centra especialmente en sus vivencias a partir de los años sesenta, cuando se incorpora a Prensa Española, grupo en el que permanecerá hasta que se produce su retirada el 27 de diciembre de 1979. Blanco y Negro sería su primer destino para recalar posteriormente en $A B C$, donde ejerció de redactor jefe de páginas gráficas, jefe de colaboraciones, subdirector, director en funciones y director adjunto, entre otras responsabilidades.

El grave episodio que analiza esta investigación ha estado rodeado de un gran oscurantismo que ahora se pretende corregir sacando a la luz fuentes documentales primarias a las que se ha tenido acceso a través del Archivo General de la Administración del Estado (AGA), sito en Alcalá de Henares, Madrid, de obligada consulta para los investigadores de la etapa del franquismo, marco histórico en el que tiene lugar este suceso que se produjo en los albores del periódico burgalés.

El trabajo incluye una sucinta caracterización de la prensa durante el primer franquismo, el más retardatario, instalado en el estancamiento económico, la rigidez política y el aislamiento internacional. En este contexto nació la totalitaria Ley de Prensa de 1938, que ató de pies y manos a los medios de comunicación y convirtió a sus directores en auténticos censores.

El número de diarios que continuaron publicándose después de la Guerra Civil se redujo a la mitad en relación a los que se editaban durante la Segunda República. Dentro de estos, podemos diferenciar tres grandes grupos: prensa privada, de la Iglesia y del Movimiento. A pesar de la relativa variedad que aparentemente podrían haber aportado las diferentes familias periodísticas, realmente había poca pluralidad en el universo periodístico franquista, pues la censura previa y las consignas los igualó y homogeneizó "hasta extremos que hoy nos parecerían irrisorios" (Pizarroso, 1989: 246). 
Las constantes generales de la Prensa del Movimiento y las singulares condiciones en las que se fundó $\mathrm{La} \mathrm{Voz}$, que nació bajo la fórmula jurídica de Sociedad Anónima y, por tanto, bajo la doble dirección de los responsables políticos de Madrid y Burgos, permitirán adentrarnos en los conflictos que se vivieron en la Redacción y que acabaron con el cese fulminante de Pedro de Lorenzo y Eduardo Bort.

\section{Estado de la cuestión}

La prensa durante el franquismo se encontraba en las antípodas de la que había existido durante la Segunda República. Su concepción liberal quedó sustituida por otra de corte totalitario, donde los golpistas mantuvieron un férreo control del sistema de comunicación y de sus principales elementos: medio, emisor y mensaje. Merced a la Ley de Prensa de 1938, nacida con carácter provisional en plena Guerra Civil, pero que mantendría su vigencia durante casi 30 años, la prensa se convirtió en un brazo más del nuevo Estado. Trocada en institución nacional, se le otorga una misión propagandística y de adoctrinamiento de la población. La ley "plasmó un modelo de control periodístico que, sin ambages, merece el calificativo del más restrictivo en la historia de España" (Chuliá, 2001: 42-43). Así lo cree también Carlos Barrera (1995: 44), para quien "fue una ley autoritaria sin paliativos, en consonancia con el contexto en la que se creó y con el significado político global del nuevo Estado que se pretendía crear".

Se acaba con la pluralidad informativa, se impone la censura previa y se riega las redacciones de consignas encaminadas a construir una imagen positiva del régimen. El periodismo desempeñaba, pues, una función de enorme magnitud en la España franquista en su lucha diaria por inculcar principios, actitudes, y formas de comportamiento gracias a las cuales los españoles apoyarían la causa de Franco (Martín de la Guardia, 2008: 20-21). Se produce, además, una radical depuración de la profesión periodística, que se llevó a cabo mediante la Ley de Responsabilidades Políticas, la aplicación de la jurisdicción militar y el Registro Oficial de Periodistas.

Con la victoria del bando rebelde se reduce drásticamente el número de publicaciones: desaparecen casi 200 cabeceras de diarios, subsisten 54 y surgen otras 50 . ¿Qué prensa, además de la del Movimiento, sobrevive a la dictadura? Las empresas periodísticas a las que se permite seguir adelante son las de Editorial Católica, cuyo principal exponente era Ya; periódicos católicos de empresas privadas, como Diario Regional (Valladolid); monárquicos como $A B C$ (Madrid y Sevilla), o los carlistas, cuya principal cabecera era El Pensamiento Navarro (Pamplona). Resultaba misión imposible identificar unos de otros, iguales como gotas de agua que eran. El sistema de censura y consignas, así como el control de las fuentes informativas a través de la agencia Efe y sus filiales, los convirtió en auténticos calcos -por lo menos durante todo el primer franquismo-, de forma que los lectores tenían serias dificultades para distinguirlos, porque sus contenidos eran los mismos. No obstante, los diarios movimentistas sí presentan algunos rasgos singulares. 


\subsection{Un emporio de cabeceras incautadas}

La Prensa del Movimiento surge durante la Guerra Civil como consecuencia de las incautaciones ${ }^{1}$ que los sublevados realizaron de los periódicos republicanos. Estas cabeceras constituirían el botín de guerra de la Falange, en la medida que iba apoderándose de los bienes y patrimonio de partidos y agrupaciones que formaron el Frente Popular. Con el Decreto de Unificación de abril de 1937, y la constitución del nuevo partido oficial, Falange Española Tradicionalista y de las JONS, estas publicaciones pasarán a depender del Estado. Su creación oficial se realizó por Ley de julio de 1940. Para entonces, la Prensa del Movimiento constituía ya un auténtico emporio mediático dirigido férreamente desde Madrid y formado por más de 40 cabeceras diseminadas por toda la geografía española. Su máximo exponente fue Arriba, el buque insignia de esta cadena que, desde Madrid, marcaba la línea editorial.

El nacimiento de estos periódicos tuvo su razón de ser en motivos ideológicos. Su finalidad no consistía en la obtención de beneficios monetarios, sino en la legitimación de un régimen que se había impuesto por la fuerza y la violencia. La divulgación de un ideario acorde con las necesidades cambiantes de la dictadura y que asegurara su continuidad constituía su principal objetivo. Lejos de proponerse un fin mercantil, serán "mitad políticos, mitad culturales" (Iglesias, 1975: 70-71), por lo que tuvieron que sostenerse con subvenciones de la Delegación Nacional de Prensa y Propaganda. Sin embargo, "aquí radicó uno de los dramas de esta amplísima red de medios de comunicación" (Martín de la Guardia, 1994: 61), porque con el paso del tiempo tuvieron que competir dentro de las leyes del mercado. Su poca atención al apartado económico, y a pesar de los privilegios de los que disfrutaron con respecto a la prensa privada, hizo que desde el primer momento, salvo pocas excepciones, atravesaran dificultades económicas.

Por sus contenidos, apenas se diferenciaban de los demás rotativos. En cuanto medios dependientes absolutamente del poder, "auténticos altavoces de los políticos", es lógico que la homogeneidad entre ellos fuera completa y que "apenas hubiera diferencia entre los distintos diarios, por muy distantes geográficamente que estuvieran" (Zalbidea, 1996: 152).

El panorama periodístico experimentará algunos cambios significativos en los años sesenta, en consonancia con la transformación de la sociedad española. Fruto de este cambio fue la nueva Ley de Prensa e Imprenta de 1966, que pese a su tímido aperturismo, constituyó la grieta que aprovecharon los periódicos privados -no los del Movimiento, que siguieron defendiendo a machamartillo las excelencias del régimen-, y en especial las revistas, para ir abriendo el camino hacia la liberalización informativa. 


\section{Los directores en la prensa franquista}

La Guerra Civil supuso un trágico paréntesis en el desarrollo de la actividad informativa. La profesión de periodista fue una de las que, proporcionalmente, sufrió un mayor número de bajas y hubo de soportar durante más tiempo persecuciones, encierros y exclusión de toda actividad ${ }^{2}$.

La Ley de Prensa de 1938 definía al periodista como "apóstol del pensamiento y de la fe de la nación recobrada a sus destinos" y de un "digno trabajador al servicio de España". En consonancia con este heroico papel que el franquismo reservaba a los periodistas, su control y vigilancia alcanzó cotas inigualadas en toda la historia contemporánea del país: se realizó una depuración entre los profesionales; se organizó el Registro Oficial de Periodistas, ROP -de 4.000 expedientes que se tramitaron, solo fueron inscritos en el ROP 1.800-; se dispuso su formación y se inspeccionó su actividad. A los periodistas rojos o tibios se les impediría ejercer la profesión.

Además, les afectaba (Núñez, 1997b: 206) la Ley de Responsabilidades Políticas de 10 de febrero de 1939, con sanciones económicas que completaban las penales para aquellos que, por acción u omisión, no hubiesen trabajado por el triunfo de los golpistas y, finalmente, la aplicación de la jurisdicción militar a través del Tribunal Militar de Prensa.

Pero la configuración de una clase periodística sumisa con el poder no se quedaba sólo en esta purga depurativa, sino que se introdujeron otros mecanismos para encuadrar a la profesión. La formación de periodistas se organizó a través de cursillos de especialización anuales que daban derecho a la inscripción en el ROP. Posteriormente, por Orden de 17 de noviembre de 1941, se creó la Escuela Oficial de Periodismo, dependiente de la Delegación Nacional de Prensa y Propaganda (DNPyP). Un mes más tarde, y con la creación del Sindicato Nacional de Papel, Prensa y Artes Gráficas, todos los periodistas quedaban encuadrados, así como la totalidad de las asociaciones de la prensa de España, una vez depuradas sus cúpulas directivas y sus asociados (Chuliá, 2001: 234).

Los periodistas pasaban así a convertirse en profesionales al servicio del poder y sometidos también a una severa vigilancia para mantenerlos alejados de las tentaciones del "libertinaje democrático" (Sinova, 1989a: 39-82). Más estrecha aún, si cabe, era la que se practicaba con los directores de periódicos. Los propietarios de estos no pudieron elegir al director de su publicación, pues esta prerrogativa la concedía el ministro del Interior, quien también podía "remover" a quien había designado. Fueron sonadas las imposiciones de directores que se produjeron en $A B C$, con José Losada (1940-1946); Ya, con Juan José Pradera (1939- 1952); La Vanguardia, con Luis de Galinsoga (1939-1960), y El Alcázar, con Jesús Evaristo Casariego (19391944). La facultad de designar al personal directivo se convirtió "en una herramienta para colocar en la dirección de los periódicos, máximo cargo responsable de su contenido y orientación, a personas de confianza, lealtad y amistad clara con el régimen" (Rodríguez, 2002: 102). 
Los periódicos, ya fueran privados o del Movimiento, compartían este rasgo en común: a todos ellos se les imponía el director. El fin que se buscaba era, naturalmente, amarrar los contenidos y que la realidad que asomara a los diarios fuera única, homogénea y al servicio del régimen. Los directores se convirtieron de facto en censores a partir de los años cincuenta -en Burgos se adelantó a 1945³-, cuando se puso en práctica la censura delegada en provincias para descargar de trabajo a los censores, que recibían las normas orientadoras de su tarea del Ministerio competente.

Durante sus primeros 5 años $\mathrm{La} \mathrm{Voz}$ de Castilla tuvo prácticamente un director por año. En total, sumó 18 a lo largo de sus 30 años de vida. La interinidad que les caracterizó, junto con su procedencia foránea, hizo que no sintonizaran ni con la ciudad ni con sus gentes, que les consideraban, como al periódico mismo, unos forasteros de paso por Burgos. Por el contrario, en Diario de Burgos, Esteban Sáez Alvarado sería el único director durante los 30 años de existencia del diario movimentista.

\section{La fundación de La Voz de Castilla}

El 1 de septiembre de 1945 se puso en marcha el último periódico de la Prensa del Movimiento, La Voz de Castilla. Para entonces, la cadena estatal contaba ya con otros 37 .

Sorprende que en una ciudad tan conservadora como Burgos, rendida desde el primer momento de la contienda civil a los golpistas, fuera necesario contar con otro medio que poco más había de aportar a las consignas defendidas ya, y con entusiasmo, por Diario de Burgos (Seoane y Saiz, 2007: 241). Pero lo cierto es que el entonces jefe provincial del Movimiento y gobernador civil, el santanderino Manuel Yllera, así lo quiso y no paró hasta conseguir abrir La Voz de Castilla. Fue, por tanto, su inspirador y valedor.

Como hemos venido diciendo, la Prensa del Movimiento nació con una importante infraestructura de bienes muebles e inmuebles, muchos de ellos incautados durante la guerra. $\mathrm{La} \mathrm{Voz}$ de Castilla no será una excepción y arrancará con maquinaria incautada, en el mes de noviembre de 1936, a la editorial Castro, sita en el barrio madrileño de Carabanchel ${ }^{4}$. Sin embargo, debido a que era insuficiente para poner en marcha el periódico, se reforzó con una máquina plana enviada por la DNPyP procedente de los diarios sevillanos del Movimiento FE y Sevilla ${ }^{5}$, así como con otra maquinaria comprada por la propia Jefatura Provincial del Movimiento.

El proyecto inicial del Yllera contemplaba asociarse con Diario de Burgos. Así lo contaba él mismo.

En la jefatura provincial del Movimiento teníamos varias máquinas de imprenta y con este motivo tuve la idea de, acoplándolas al periódico existente, crear con mis medios y los de ellos un periódico de la categoría que Burgos se merece, pidiendo tan solo que me concedieran exclusivamente el control político. No se interpretó debidamente mi proposición y por el contrario se me vino a proponer, no el control político del periódico sino el cincuenta por ciento de participación en los beneficios. Ante semejante oferta que casi puedo adivi- 
nar fue hecha a mi persona reaccioné como es lógico reaccionar en uno de estos casos y desde entonces les prometí que la creación de un nuevo periódico sería un hecho, porque no es mi norma mezclarme en asuntos turbios ${ }^{6}$.

Conocemos interesantes detalles de estos comienzos a través del informe "Antecedentes y fundación de La Voz de Castilla" ", donde se narra que Yllera consideraba "urgente" este proyecto por tres motivos: primero, por "las deficiencias de Diario de Burgos"; segundo, como "medio de vida de muchos camaradas burgaleses, que podrían encontrar solucionado su problema de trabajo en la redacción, confección y administración del periódico", y en tercer lugar, "y principal: por disponer de un órgano de combate que sirva de enlace y portavoz de las actividades de la Falange". Y continúa el informe, que si bien no lleva firma ni destinatario, parece haber sido redactado por alguien de la vieja guardia de la Falange burgalesa muy próximo a Yllera y que siguió muy de cerca los pasos dados por el gobernador para la creación del diario:

Para la formación del nuevo periódico se dispone de dinero en cantidad más que suficiente, ya que por entonces cuentan las J.A.N.S. con un capital de ocho o nueve millones de pesetas, procedentes de multas gubernativas, cuarenta por ciento de las impuestas por la Fiscalía de Tasas, y otra serie de impuestos, subsidios y sobretasas que el jefe provincial, como gobernador civil, impone sin sujeción o forma legal alguna 8 .

La Falange burgalesa acogió la idea de disponer de un medio propio con entusiasmo, si bien no acabará de ver con buenos ojos las dudas que le entran a Yllera respecto a la forma jurídica que habrá de adoptar. Baraja varias posibilidades. Descarta convertirlo en un órgano del partido, dependiente de la Jefatura Provincial, porque estaría sometido al control de la Delegación Nacional de Prensa; se le ocurre, aunque se deshecha, crear una fundación mantenida por la J.A.N.S. (Junta de Ayuda Nacional Sindicalista) para "conseguir que el periódico no sea de derecho del partido, aunque sí de hecho". Finalmente, apuesta por crear una Sociedad Anónima en la que la J.A.N.S. tendría el 51\% de las acciones, reservando el 49\% restante para particulares, y en concreto para "camisas viejas". Esta tercera opción le parecía a Yllera la más viable, pues impediría la intervención del periódico por las jerarquías nacionales del partido, dado que como sociedad particular se administraría por sus propios medios ${ }^{9}$.

Realmente, la fórmula elegida no era más que una maniobra del gobernador para convertirse en el dueño y señor del periódico, en la creencia de que evitaría así la intervención y el control que la DNPyP ejercía habitualmente en la prensa. Lo cierto, por tanto, es que el periódico se fundó con fondos de FET y de las JONS de Burgos y ningún particular invirtió en él un solo céntimo, convirtiéndose en el órgano del gobernador civil ${ }^{10}$.

La vieja guardia de la Falange burgalesa, que quiere un periódico del partido, ve con recelo cómo Yllera parece distanciarse de sus camaradas para acabar influenciado por el sacerdote y a la sazón delegado provincial de Educación Nacional, Bonifacio Zamora; o cómo coloca en la Gerencia del diario a su secretario particular, pese a que sus únicos méritos profesionales se resumían en haber sido banderillero y crupier de una 
casa de juegos de Bilbao ${ }^{11}$. En la lista de beneficiados figuraba el propio padre de Yllera, que se trasladó a Burgos en los prolegómenos de la creación del periódico.

En el Banco Mercantil hay una cuenta corriente por valor de un millón de pesetas que figura a nombre de Yllera padre, cuenta utilizada para estos negocios y que parece ser procede de las J.A.N.S., donde no hay entradas ni salidas que se controlen. Solo existe una determinada cantidad como capital [...] y que se administra a capricho y antojo del jefe de las Juntas ${ }^{12}$.

Un arranque sorpresivo, por tanto, el del periódico burgalés en comparación con la fundación de otros de la cadena de Prensa del Movimiento que, desde sus comienzos, tuvieron clara su propiedad y sus objetivos propagandísticos más que monetarios. La Voz de Castilla, sin embargo, nace con pretensiones de campar a sus anchas, un díscolo entre tanto periódico dirigido con mano de hierro desde Madrid. Sus fines serán, como en el resto de periódicos de la cadena, ideológicos, al servicio del régimen. Pero el proyecto iba más allá, buscaba también la obtención de beneficios económicos para sus adalides; de ahí el interés de su mentor de que no estuviera sujeto al control administrativo y económico de la Delegación Nacional de Prensa y Propaganda.

El contrato que se firma entre la Vicesecretaría General del Movimiento y la Jefatura Provincial declaraba a la DNPyP propietaria del periódico a todos los efectos, si bien lo cedía en uso y durante un año prorrogable, a la Jefatura del Movimiento en Burgos ${ }^{13}$.

La publicación, por tanto, arrancó con dos cabezas: la de la DNPyP, que se aseguraba el control de los contenidos con el nombramiento de la Redacción y del director -recordemos que ya entonces era el responsable de la censura-, y la de la FET y de las JONS de Burgos, personalizada en su responsable, que se hacía cargo de la explotación y corría con todos los gastos, también los de la Redacción.

\section{La imposición de Pedro de Lorenzo}

El régimen no daba importancia a la figura del director por cuanto la consideraba, simplemente, una correa de transmisión de las bondades del franquismo. La única cualidad que debían poseer para llegar a la Dirección de un periódico del Movimiento era la fidelidad y el servilismo al régimen, que premiaba a los periodistas afectos con este destino.

Lo mismo sucedía con los redactores, que en su mayoría eran jóvenes inexpertos enviados de otras provincias. Generalmente, procedían de la propia Escuela de Periodismo, de un curso de formación o de otros periódicos de la cadena. Y, efectivamente, este era el perfil de la primera y jovencísima Redacción de La Voz de Castilla, comandada por el vallisoletano Demetrio Ramos Pérez, a quien con 28 años se le encomienda la misión de poner en marcha un nuevo diario en Burgos con periodistas recién salidos de la Escuela Oficial de Periodismo. 
La doble propiedad que caracterizó los comienzos de $\mathrm{La}$ Voz tensionó sobremanera a los integrantes de la Redacción, que se vieron en medio del fuego cruzado que mantenía la Jefatura Provincial del Movimiento y la DNPyP por el control del periódico. Estas complicadas relaciones hicieron acto de presencia con motivo de la sustitución de Demetrio Ramos, que tras permanecer dos meses en la Dirección, volvió a sus quehaceres de catedrático de Geografía e Historia en el Instituto Zorrilla de Valladolid.

Hasta tanto se producía el relevo, el redactor jefe, Eduardo Bort, fue el director en funciones, si bien a finales de octubre "se presentó en el periódico el Sr. Bureba, quien asumió inmediatamente la dirección"14, sin que nada se comunicara oficialmente a los redactores ni al personal de Talleres. Yllera pretendió así aprovechar la salida de Demetrio Ramos para colocar a una persona de su confianza, en este caso a Bernardo Bureba, entonces director de Hierro.

Por aquellos días Bort abrió una carta que, aunque no iba a él dirigida y pensando que se trataba de un error, contenía la felicitación de la DNPyP al nuevo director de $\mathrm{La} \mathrm{Vz}$ de Castilla, Pedro de Lorenzo. Pronto sabría lo ocurrido, concretamente el 5 de noviembre, cuando atendió la llamada telefónica del mismísimo delegado nacional de Prensa, Juan Aparicio:

- ¿Quién hay al aparato?- Soy Bort. A tus órdenes, Aparicio.

- Di al director que se ponga.

- ¿Qué director? Ramos está en Valladolid y Bureba esta tarde no ha venido. Debe haberse marchado a Bilbao.

- Ninguno de ellos es el director. El director es Pedro de Lorenzo ${ }^{15}$.

Efectivamente, el nuevo director había llegado el día anterior a Burgos y lo primero que hizo fue acudir a cumplimentar al gobernador, quien después de negarse a recibirle en el primer intento, acabó atendiéndole para manifestarle que él ya tenía candidato para dirigir el periódico. Juan Aparicio no tardaría en telefonear a Yllera: "O es Pedro de Lorenzo el director o cierro el periódico". Aquella misma noche el nuevo responsable de la Redacción se incorporó a La Voz de Castilla.

Pedro de Lorenzo había sido alumno de la Escuela Oficial de Periodismo, donde luego ejercería como profesor en la especialidad de "Estilo", y ya tenía tras de sí la experiencia de haber dirigido El Diario Vasco, haber sido redactor de Arriba, colaborador de Ya y fundador de la revista Garcilaso. Intuía (Lorenzo, 1983: 37) que su estancia en Burgos iba a ser corta. "Algo me decía que no era ese el camino", confesaba respecto a sus destinos en "la prensa de provincias", donde echaba de menos "las alas retóricas madrileñas" y los medios necesarios para sacar adelante un periódico. En sus memorias no hace referencia alguna a los problemas que vivió en el diario burgalés ni tampoco a los motivos que propiciaron su vuelta a Madrid. 


\section{El pulso de Yllera}

Ni cuatro meses llegó a permanecer en su puesto de director Pedro de Lorenzo. Él y Eduardo Bort recibieron idénticas cartas de despido el 19 de febrero de 1946. En ellas se alegaba "desorganización" en sus cometidos. El gerente, Vicente de la Brena, que se encargó de entregarles en mano la misiva, les ordenó además abandonar Burgos so pena de cárcel. Por su parte, Yllera comunicó esta decisión al director general de Prensa, Tomás Cerro, argumentando "faltas graves que desde hace tiempo vienen perjudicando hondamente a la empresa de $\mathrm{La} \mathrm{Voz}$ de Castilla que hubieran podido poner al periódico en trance de hundimiento definitivo, de no haberlas atajado oportunamente". Le informaba igualmente de que se había hecho cargo de la dirección el redactor José $\mathrm{M}^{\mathrm{a}}$ de Mena.

Los afectados hubieron de personarse en la Comisaría de Burgos al día siguiente y escuchar, de boca del comisario jefe, que a las 12 de la noche de aquel mismo día debían abandonar la provincia de Burgos. No solo se les echaba del periódico, sino que también se les desterraba. La versión que ofrece Santiago Castelo (1973: 41) en la biografía sobre Pedro de Lorenzo es que la expulsión de la provincia habría afectado en exclusiva al redactor jefe y que el director no lo consintió: "Por esta diferencia con el gobernador es desterrado [De Lorenzo] de Burgos".

Ambos periodistas pidieron amparo a la Asociación de la Prensa, que comunicó su malestar al director general de Prensa y al presidente de la Federación de Asociaciones de la Prensa. La cuestión parece que se resolvió bien, pues los interesados fueron repuestos por la Dirección General ${ }^{16}$, si bien se les suspendió de empleo hasta tanto se instruyese el oportuno expediente.

El expediente que se abre es muy voluminoso y por él nos hemos enterado de los pormenores de este embarazoso incidente ${ }^{17}$. Lo primero que hace la Dirección General de Prensa cuando tiene conocimiento de estos despidos es ponerse en contacto telefónico, el día 21 de febrero, con el delegado provincial de Educación Popular, Bonifacio Zamora, que como hemos dicho era el hombre de confianza de Yllera en el periódico, para requerirle que ordenara la restitución a sus puestos de Pedro de Lorenzo y Eduardo Bort, "con amenaza, en caso contrario, de ser destituido". Lejos de cumplir la orden, según explica el interesado en su informe, "porque la propiedad del periódico me era dudosa", se declaró en rebeldía y se negó a acatarla. Pocos días después enviaría informes a Madrid con la versión de la empresa, donde se cargaba muy duramente contra los periodistas. Se acusaba a Pedro de Lorenzo "de llevar una vida privada inmoral y de haber dejado de publicar algunas noticias de gran importancia, así como de desprecio absoluto por los temas burgaleses", y a Eduardo Bort, de estar embriagado frecuentemente, olvidar el envío de originales a talleres y de perder algunos de ellos.

Bonifacio Zamora adjuntó también las declaraciones que personalmente tomó a cada uno de los redactores, colaboradores y personal de Talleres del diario a quienes poco menos que obligó a firmar que eran ciertas las acusaciones formuladas por la empresa contra el director y redactor jefe. 
Antes de que el expediente abierto concluyera con la restitución de los periodistas a sus funciones, Bonifacio Zamora fue cesado y sustituido por Ángel Temiño, quien también informó sobre lo acaecido. Daba cuenta de las maniobras de su predecesor en el cargo y del que denominaba "su protegido", José María de Mena, para hacerse con las riendas del periódico y de la aversión manifiesta de Zamora contra Diario de Burgos, mientras que se entregó "en alma y vida" a viajes y gestiones propagandísticas de La Voz de Castilla. Pero, sobre todo, afirmaba Temiño, "quiere dirigir el periódico".

A tal punto que cuando el director de $L a V z$ le hace ver que es él quien marca las directrices de su periódico, el delegado deja de acudir a la redacción y comienza su ofensiva que culmina en la destitución de dicho director, así como del redactor jefe. De esta forma, su protegido, José $\mathrm{M}^{\mathrm{a}}$ de Mena, a quien inspira y dirige en todos sus artículos, se convierte en el nuevo director del periódico, a pesar de no contar con el carnet profesional ni estar inscrito en el Registro, toda vez que es un alumno de la Escuela Oficial de Periodismo que no ha concluido sus estudios ${ }^{18}$.

Incorporaba Temiño a su informe otro realizado por Pedro de Lorenzo al poco tiempo de llegar a La Voz de Castilla. En este escrito, De Lorenzo ya se había percatado de que José $\mathrm{M}^{\mathrm{a}}$ de Mena, al que calificaba de "agresivo, ambicioso y servil al mismo tiempo", era un problema para la Redacción y pedía su traslado ${ }^{19}$. Le atribuía la capacidad para la intriga.

Con el tiempo, entre obedecer a Bonifacio Zamora, es decir, a la empresa, y obedecer a la dirección optó por la obediencia a la primera e inició una intriga feroz contra la dirección, el redactor jefe y sus compañeros. Comenzó a esconder las noticias más importantes del día que llegaban por teletipo, de forma que se culpabilizaba al redactor jefe de que al día siguiente en La Voz de Castilla no apareciera publicada la noticia más importante ${ }^{20}$.

Consideraba el director que la Redacción era "sana, llena de buenos deseos" y que la amistad con el otro periódico podía "ser perfecta y las simpatías de Burgos unánimes si en medio de todo no anduviera Mena, apoyado por Bonifacio Zamora"21, concluía.

La fulminante decisión del Ministerio de Educación Nacional de destituir a su representante en Burgos por negarse a cumplir la orden de sus superiores no fue comunicada ni al propio interesado ni al gobernador civil, a sabiendas de que Zamora no hizo sino seguir las órdenes del propio Yllera para deshacerse de los periodistas.

Como quiera que el gobernador no acató el nombramiento de Ángel Temiño para sustituir a Zamora y se negó a que tomara posesión de su cargo en el Gobierno Civil, se produjo la insólita circunstancia de que hubo de viajar hasta Burgos un inspector de la Subsecretaría de Educación Popular para que, ante notario, tomara posesión el nuevo cargo provincial. El funcionario quedó poco menos que impactado por lo que se encontró en La Voz de Castilla:

El periódico no es de Falange porque lo integra una Sociedad Anónima. No es particular, tampoco, porque se fundamenta en el dinero de los fondos propios de la Falange. El periódico vive su vida sin censura ni intervención estatal de ninguna clase, por su propia virtud. Los efectos de la consigna de su "mentor" se deja sentir 
en el miedo que siente todo el personal directivo y administrativo del mismo en tratar, rozarse o establecer cualquier contacto con los servicios de la Subsecretaría de Educación Popular ${ }^{22}$.

Yllera no escatimó esfuerzos para salvar a su hombre de confianza. En una carta dirigida al ministro de la Gobernación ${ }^{23}$ culpa a los propietarios y al director de Diario de Burgos de haber sido los causantes de la destitución de Bonifacio Zamora. Según decía, la aparición de La Voz de Castilla y su triunfo rotundo hizo que la competencia se dedicara a intrigar contra el delegado de Educación Popular. Se despedía con este ultimátum:

Si se desea que continúe de gobernador civil pido dos cosas: $1^{\circ}$ ) Contestación a todos los escritos que dirigí al subsecretario de Educación Popular y al Sr. Ministro de Educación Nacional. $2^{\circ}$ ) Aceptación para delegado de Educación Popular de la persona que yo proponga.

Ninguno de sus dos requerimientos fue aceptado. Lejos de que así fuera, la reacción del Ministerio fue arrebatarle la gestión del periódico, que pasó a depender íntegramente de la Delegación Nacional de Prensa y Propaganda el 1 de agosto de 1946. Además, y unos meses después, en noviembre, el incidente se cobraría también la cabeza de Yllera.

Ni Pedro de Lorenzo ni Eduardo Bort volvieron a pisar por Burgos. Pese al beneplácito de los responsables de Prensa del Movimiento para que se incorporaran a La Voz de Castilla, ninguno de los dos osó regresar.

\section{Conclusiones}

El acceso a fuentes documentales, como el Archivo General de la Administración (AGA), ha permitido conocer datos inéditos referidos a la creación del diario del Movimiento, La Voz de Castilla, y en concreto lo ocurrido con el periodista Pedro de Lorenzo, que en menos de cuatro meses pasó de ser el director del rotativo a un proscrito en Burgos.

Las razones de este suceso, en el que también se vio involucrado el redactor jefe Eduardo Bort, hay que buscarlas en las peculiares características con las que nace el periódico, que parte del empeño personal del gobernador civil y jefe provincial del Movimiento, Manuel Yllera, de disponer de un medio de comunicación propio que respondiera a sus intereses personales. Debido a que no consiguió llegar a un acuerdo con Diario de Burgos, único que se editaba en la ciudad, para explotar la publicación conjuntamente, impulsó uno nuevo.

¿Y cómo lo hace? Constituye una empresa privada bajo la forma jurídica de Sociedad Anónima para evitar su dependencia administrativa de la Delegación Nacional de Prensa y Propaganda. Siendo un periódico de la Falange, creado con dinero de la Junta de Ayuda Nacional Sindicalista (JANS), recurre a esta artimaña para mantener el control absoluto del diario, sin que en su devenir intervenga la 
dirección de Madrid. Yllera pretendía que la publicación, que formal y oficialmente pasa a formar parte de la Prensa del Movimiento, funcionara con plena autonomía de la dirección nacional. El periódico, pues, nace con la doble titularidad de la DNPyP y de la FET y de las JONS de Burgos.

$\mathrm{La} \mathrm{Vz}$ de Castilla nació con una finalidad ideológica, pero también económica. $\mathrm{Su}$ fundador no descartó convertirla en una empresa rentable. Estaríamos así ante una nueva característica singular de $\mathrm{La} \mathrm{Vz}$ de Castilla respecto a la creación de los diarios de la Prensa del Movimiento, puesto que el periódico salió con una clara vocación empresarial. Yllera quería un altavoz ideológico, sí, pero también un negocio. Para llevar a buen puerto este objetivo se apoyó en todo momento en personal de su absoluta confianza. En este proyecto le estorbaban los directores impuestos por la DNPyP, como Pedro de Lorenzo, que estaban a las órdenes de Madrid. Como responsables ya de la censura cuando nace La Voz de Castilla, recaía sobre ellos el control de los contenidos y la publicación de las consignas.

Yllera no se conformaría solo con explotar económicamente el nuevo medio de comunicación. Quiso, desde el primer momento, intervenir en sus contenidos y echó un pulso a la DNPyP pretendiendo nombrar al director. Las luchas de los dos organismos por controlar $\mathrm{La} \mathrm{Voz} \mathrm{de} \mathrm{Castilla} \mathrm{convirtieron} \mathrm{a} \mathrm{la} \mathrm{Redacción} \mathrm{en} \mathrm{un} \mathrm{campo} \mathrm{de}$ minas y provocó el despido y destierro de Pedro de Lorenzo y Eduardo Bort.

La DNPyP no se anduvo por las ramas e impuso su voluntad, dejando claro quién mandaba en el periódico. Ante la desobediencia e incumplimiento de las órdenes de restituir en sus puestos a los afectados, rodaron las cabezas de Bonifacio Zamora, el comisario político del gobernador en el periódico, y meses después la del propio Yllera, que antes tuvo que ver cómo desde Madrid le arrebataban el diario, que pasó a integrarse plenamente en la Prensa del Movimiento.

\section{Referencias bibliográficas}

ÁlVAREZ, J. T. et al. (1989). Historia de los medios de comunicación en España. Periodismo, imagen y publicidad (1900-1990). Barcelona: Ariel.

BARRERA, C. (1995). Periodismo y Franquismo: De la censura a la apertura. Barcelona: Ediciones Internacionales Universitarias.

BULLÓN DE MENDOZA, A.; TOGORES, L. E. (coord.) (2002). Revisión de la Guerra Civil Española. Madrid: Actas.

CASTELO, S. (1973). Pedro de Lorenzo. Madrid: EPESA.

CHULIÁ, E. (2001). El poder y la palabra. Prensa y poder político en las dictaduras. El régimen de Franco ante la prensa y el periodismo. Madrid: Biblioteca Nueva.

GARCÍA, J. A.; GUTIÉRREZ, J. F.; SÁNCHEZ, I. (ed.) (2002). La comunicación social durante el franquismo. Málaga: Centro de Ediciones de la Diputación Provincial de Málaga. 
GONZÁLEZ CALLEJA, E. (1990). "La prensa falangista y la prensa del Estado. Consideraciones sobre su origen y desarrollo". En TUNOÓN DE LARA, M. (dir.), Comunicación, cultura y política durante la II República y la Guerra Civil (2). Bilbao: Universidad del País Vasco. p. 495-517.

GUZMÁN, E. de (1982). Historias de la Prensa. Madrid: Penthalon.

IGLESIAS, F. (1975). "Un imperio informativo: Prensa y Radio del Movimiento". En: Nuestro Tiempo, 1 (250), p. 67-77.

LORENZO, P. de (1983). Diario de la mañana. Badajoz: Universitas Editorial.

MARTÍN DE LA GUARDIA, R. M. (1994). Información y propaganda en la prensa del Movimiento. Libertad de Valladolid, (1931-1979). Valladolid: Secretariado de Publicaciones de la Universidad de Valladolid.

(2008). Cuestión de tijeras. La censura en la transición a la democracia. Madrid: Síntesis.

MATEOS FERNÁNDEZ, J. C. (1997). "Periodistas de Madrid en guerra”. En NÚÑEZ DÍAZ-BALART, M.; MARTÍNEZ DE LAS HERAS, A.; CAL MARTÍNEZ, R. (coord.), José Altabella. Libro Homenaje. Madrid: Facultad de Ciencias de la Información (UCM). p. 445-455.

MONTABES PEREIRA, J. (1989). La prensa del Estado durante la transición política española. Madrid: Centro de Investigaciones Sociológicas-Siglo XXI.

NÚÑEZ DÍAZ-BALART, M.; MARTÍNEZ DE LAS HERAS, A.; CAL MARTÍNEZ, R. (coord.) (1997a). José Altabella. Libro Homenaje. Madrid: Facultad de Ciencias de la Información (UCM).

NÚÑEZ DÍAZ-BALART, M. (1997b). “El ojo de la aguja. El carnet de periodista, el último filtro de depuración profesional en la inmediata posguerra". En: Historia y Comunicación Social, (2), p. 205-210.

PASCUAL, P. (1993). "La prensa del Movimiento vista desde dentro". En TUSELL, J. et al., El régimen de Franco (1936-1975). Política y Relaciones Exteriores (1). Madrid: UNED. p. 463-479.

PIZARROSO QUINTERO, A. (1989). "Política informativa: información y propaganda (1939-1966)". En ÁlVAREZ, J. T. et al., Historia de los medios de comunicación en España. Periodismo, imagen y publicidad (1900-1990). Barcelona: Ariel. p. 231-249.

RODRÍGUEZ VIRGILI, J. (2002). "El director de periódicos en la Ley de Prensa de 1938: El caso de Jesús Evaristo Casariego en El Alcázar”. En GARCÍA, J. A.; GUTIÉRREZ J. F.; SÁNCHEZ, I. (ed.), La comunicación social durante el franquismo. Málaga: Centro de Ediciones de la Diputación Provincial de Málaga. p. 87-102.

SEOANE, M. C. y SAIZ, M. D. (2007). Cuatro siglos de periodismo en España. De los avisos a los periódicos digitales. Madrid: Alianza Editorial.

SINOVA, J. (1989a). La censura de prensa durante el franquismo (1936-1951). Madrid: Espasa-Calpe.

ZALBIDEA BENGOA, B. (1996). La Prensa del Movimiento en España: 1936-1983. Bilbao: Universidad del País Vasco. 


\section{Notas}

1 Begoña Zalbidea (1996: 67-145) es la autora que mejor y más extensamente ha documentado y explicado las incautaciones de la prensa republicana que dieron lugar a la Prensa del Movimiento, la legislación en la que se apoyaron y las trabas que se pusieron a los particulares afectados que pretendían hacer reclamaciones. De interés resulta también la consulta de la obra de Juan Montabes Pereira (1989: 7-19), y otras en las que se analiza la Prensa del Movimiento desde diferentes aspectos y donde se incide en sus orígenes. Tal es el caso de los artículos de Eduardo González Calleja (1990: 495-517) y Pedro Pascual (1993: 463-479), u obras colectivas como la de Jesús Timoteo Álvarez y otros (1989); Juan Antonio García Galindo y otros (2002) y Alfonso Bullón de Mendoza y Luis Eugenio Togores (2002).

2 Para conocer los pormenores de la represión de la que fue objeto la profesión periodística en Madrid, puede consultarse el capítulo X de la obra de Eduardo de Guzmán (1982), y los artículos de Mirta Núñez Díaz-Balart (1997a) y Juan Carlos Mateos Fernández (1997).

3 Informe del delegado nacional de Prensa al vicesecretario de Educación Popular proponiendo la destitución de censores. Madrid, 24 de abril de 1945. A.G.A., M.C.S.E. (03) 49.001 21/812.

4 Expediente número 3 origen. Maquinaria en depósito del jefe de Prensa y Propaganda de Burgos, rescatada del Frente de Guerra. Negociado de Bienes Patrimoniales. Material de imprenta y mobiliario procedente de incautaciones que pasaron a ser propiedad de la Delegación Nacional de Prensa y Propaganda de FET y de las JONS. A.G.A., M.C.S.E. (03) 114.005 25/19248.

5 Proyecto de contrato de cesión del periódico La Voz de Castilla a la Jefatura Provincial del Movimiento. Madrid, 29 de diciembre de 1945. A.G.A., M.C.S.E. (03) 114.005 25/19248.

6 Carta del jefe provincial del Movimiento y gobernador civil, Manuel Yllera, al ministro de la Gobernación, Blas Pérez González. "Asunto suscitado entre este Gobierno Civil y la Subsecretaría de Educación Popular en relación con el cese y nombramiento del delegado provincial de Educación Popular". Sin fecha. Una copia de esta carta será enviada por el ministro de la Gobernación al de Educación Nacional, José Ibáñez Martín. Madrid, 23 de julio de 1946. A.G.A., M.C.S.E. (03) 49.21 Caja 66602 TOP. 72/31-32.

7 Informe. "Antecedentes y fundación de La Voz de Castilla". Sin firma. Burgos, 26 de diciembre de 1945. Ibídem.

8 Ibídem.

9 Ibídem.

${ }^{10}$ Correspondencia del funcionario de la Subsecretaría de Educación Popular, Sr. Rus, al director general de Propaganda, Pedro Rocamora, en relación con La Voz de Castilla. Burgos, 13 de junio de 1946. Cinco días más tarde, Pedro Rocamora envía copia de esta carta al director general de Prensa, Tomás Cerro. Madrid, 18 de junio de 1946. Ibídem.

11 Informe. "Antecedentes y fundación de La Voz de Castilla". Sin firma. Burgos, 26 de diciembre de 1945. Ibídem

12 Ibídem.

${ }_{13}$ Proyecto de contrato de cesión del periódico La Voz de Castilla a la Jefatura Provincial del Movimiento. Madrid, 29 de diciembre de 1945. A.G.A., M.C.S.E. (03) 114.005 25/19248.

${ }^{14}$ Informe confidencial de Eduardo Bort Carbó sobre La Voz de Castilla. Sagunto, 14 de marzo de 1946. Ibídem. 
15 Ibídem.

16 Acta Asociación de la Prensa. Burgos, 22 de febrero de1946, p. 111.

17 Expediente sobre los despidos de Pedro de Lorenzo y Eduardo Bort. A.G.A., M.C.S.E. (03) 49.21 Caja 66602 TOP 72/31-32.

18 Informe del delegado provincial de Educación Popular, Ángel Temiño. Sin fecha. Ibídem.

19 Informe del director de La Voz de Castilla, Pedro de Lorenzo. Sin fecha, pero podría ser de finales de diciembre de 1945. Ibídem.

${ }^{20}$ Ibídem.

${ }^{21}$ Ibídem.

${ }^{22}$ Informe del funcionario de la Subsecretaría de Educación Popular, Sr. Rus, al director general de Propaganda, Pedro Rocamora. Burgos, 13 de junio de 1946. A.G.A., M.C.S.E., (03) 49.21 Caja 66602 TOP 72/31-32.

${ }^{23}$ Carta del gobernador civil y jefe provincial del Movimiento, Manuel Yllera, al ministro de la Gobernación, Blas Pérez González. "Asunto suscitado entre este Gobierno Civil y la Subsecretaría de Educación Popular en relación con el cese y nombramiento del delegado provincial de Educación Popular". Sin fecha. Una copia de esta carta será enviada por el ministro de la Gobernación al de Educación Nacional, José Ibáñez Martín. Madrid, 23 de julio de 1946. A.G.A., M.C.S.E (03) 49.21 Caja 66602 TOP 72/31-32. 